\title{
Diels-Alder reactions in confined spaces: the influence of catalyst structure and the nature of active sites for the retro-Diels-Alder reaction
}

\author{
Ángel Cantín ${ }^{1}$, M. Victoria Gomez ${ }^{*}$ and Antonio de la Hoz ${ }^{* 2}$
}

\author{
Full Research Paper \\ Address: \\ ${ }^{1}$ Instituto de Tecnología Química (UPV-CSIC), Universidad \\ Politécnica de Valencia, Avda. Los Naranjos s/n, 46022 Valencia, \\ Spain and ${ }^{2}$ Área Química Orgánica, Facultad de Químicas, \\ Universidad de Castilla-La Mancha, and Instituto Regional de \\ Investigación Científica Aplicada (IRICA), Avda. Camilo José Cela \\ s/n, E-13071-Ciudad Real, Spain \\ Email: \\ M. Victoria Gomez* - Mariavictoria.Gomez@uclm.es; \\ Antonio de la Hoz* - Antonio.Hoz@uclm.es \\ * Corresponding author \\ Keywords: \\ catalysis; Diels-Alder; retro-Diels-Alder; zeolites
}

Beilstein J. Org. Chem. 2016, 12, 2181-2188.

doi:10.3762/bjoc. 12.208

Received: 28 July 2016

Accepted: 27 September 2016

Published: 13 October 2016

This article is part of the Thematic Series "Green chemistry".

Guest Editor: L. Vaccaro

(C) 2016 Cantín et al.; licensee Beilstein-Institut.

License and terms: see end of document.

\begin{abstract}
Diels-Alder cycloaddition between cyclopentadiene and $p$-benzoquinone has been studied in the confined space of a pure silica zeolite Beta and the impact on reaction rate due to the concentration effect within the pore and diffusion limitations are discussed. Introduction of Lewis or Brønsted acid sites on the walls of the zeolite strongly increases the reaction rate. However, contrary to what occurs with mesoporous molecular sieves (MCM-41), Beta zeolite does not catalyse the retro-Diels-Alder reaction, resulting in a highly selective catalyst for the cycloaddition reaction.
\end{abstract}

\section{Introduction}

The Diels-Alder reaction (DAR) is one of the most useful reactions in organic synthesis. In order to improve the yield and to avoid the reversibility of the reaction, homogeneous Lewis acids [1-4], solid acids [5,6] as catalyst, high pressures [6-8] and/or water as a solvent $[9,10]$ have been reported. In particular, and among the most interesting environmental-friendly reactions, the cycloaddition reaction occurs with high selectivity and atom economy. Moreover, Diels-Alder cycloadditions in combination with heterogeneous catalysts (i.e. doped- microporous materials) represent an interesting approach for the conversion of biomass feedstock into stable chemicals such as furfural derivatives, platform molecules which can be converted into a variety of liquid hydrocarbon fuels and fuel additives $[11,12]$. Catalysis is considered as one of the foundational pillars of green chemistry. Catalysis often reduces the energy requirements, permits the use of renewable feedstocks and less toxic reagents. Moreover, in most cases yields are improved and selectivity is enhanced or modified [13]. In this regard, hetero- 
geneous catalysis in general and zeolites in particular are remarkably efficient since they permit the replacement of toxic mineral acids and oxidants by easily recyclable catalysts [14].

One approach to improve yields and selectivity is the special confinement of the reactants and the presence of catalytic active sites, $[15,16]$ by use of microporous materials doped with metals. While pore dimensions and topology of the microporous materials can affect the selectivity of the reaction, their activity can be strongly limited by a slow diffusion of reactants and products, unless microporous molecular sieves with the appropriated pore dimensions are used as catalyst. Thus, microporous molecular sieves with optimized pore diameters and topologies can be of interest to catalyze DAR [17-26] in where different stereoisomers could be obtained. Lewis-acid centers contained within the framework of zeolite beta $(\mathrm{Zr}-\beta, \mathrm{Sn}-\beta)$ are useful catalysts in the Diels-Alder reaction for the production of bio-based terephthalic acid precursors, one of the monomers for the synthesis of polyethylene terephthalate that is used for the large-scale manufacture of plastic bottles among others. The authors do not find transport limitations within the zeolite framework to the rate of the reaction [27]. Interestingly, when Brønsted acid containing zeolites (Al- $\beta$ ) are used as catalyst, there is a decrease in the Diels-Alder reaction selectivity [28].

The DAR of cyclopentadiene with $p$-benzoquinone is a wellknown example of cycloadditions, and some results can be found on the control of the selectivity to the different isomers. In homogeneous phase, equimolar amounts of diene and dienophile afford two isomers, the endo as the major and the exo as the minor product. The addition of a second equivalent of cyclopentadiene affords mainly the endo-anti-endo product as major isomer, and the endo-anti-exo product as the minor isomer. While CsY zeolite enhances the selectivity to the endoanti-exo isomer [29], the mesoporous material MCM-41 enhances the conversion to the endo-anti-endo isomer as has been shown in a previous work [30]. However, MCM-41 in the form of aluminosilicate that contains Brønsted sites enhances the retro-Diels-Alder reaction increasing the selectivity to the endo-anti-exo isomer. Therefore, the framework and extra framework composition of mesoporous materials and zeolite could be used to control the selectivity of the DAR of cyclopentadiene and $p$-benzoquinone.

In the present work, a series of large pore, pure silica zeolites (in which rate enhancement can only occur by spatial confinement) and the same structures but containing framework Brønsted or Lewis acid sites have been studied for the DAR between cyclopentadiene and $p$-benzoquinone. The effects of pore dimensions and catalyst composition on diffusivity and selectivity with respect to the retro-Diels-Alder reaction (retroDAR) are discussed.

\section{Results and Discussion}

As it was described previously [30], the Diels-Alder reaction (DAR) between cyclopentadiene and $p$-benzoquinone follows the reactions outlined in Scheme 1.

As expected, the Diels-Alder cycloaddition provides the kinetically controlled endo isomer that very rapidly reacts with a second molecule of the diene to give again the kinetic endoendo isomer. It is remarkable that neither the thermodynamic exo isomer nor the secondary exo-endo and exo-exo products were detected under our reaction conditions. Thus, the observed products, endo-endo and endo-exo are obtained in different ratio according to the reaction conditions. This ratio can change with the time since the retro-Diels-Alder reaction appears as a competitive reaction. In this way, the final molecular product can revert to the initial endo isomer, which in turn can react again with a new cyclopentadiene molecule. This is

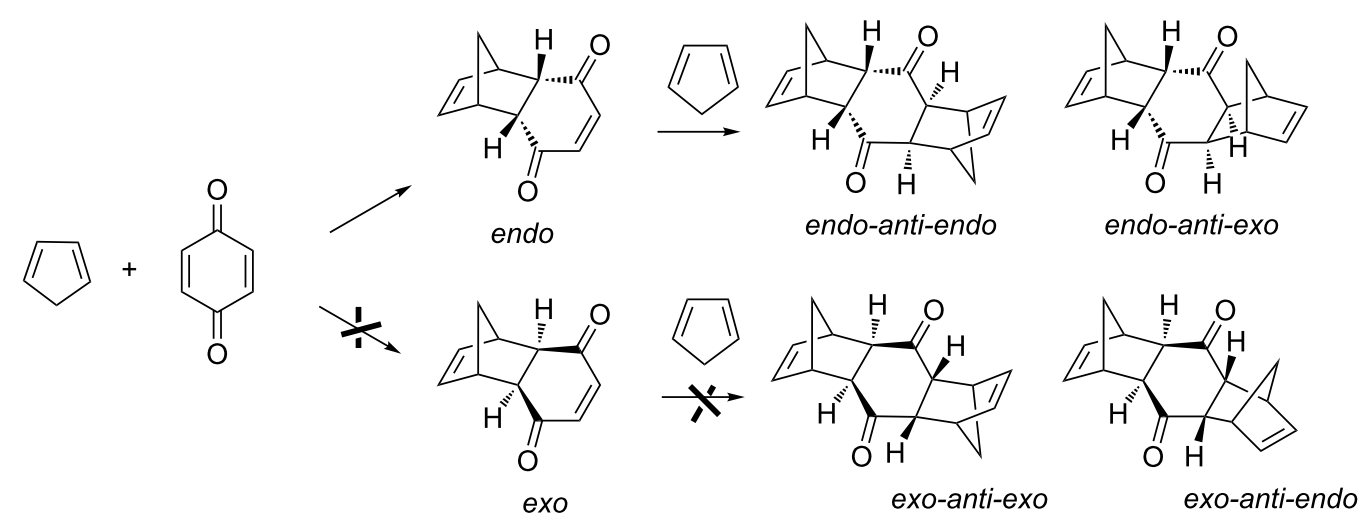


reflected in the distribution products by a decrease of the endoendo isomer (kinetic control product) jointed to an increase of the endo-exo (thermodynamic control product).

\section{Influence of catalyst surface}

We have seen that the DAR between cyclopentadiene and $p$-benzoquinone takes place thermally. The effect of confinement of the reactant within the pores of the catalyst can decrease the entropy of the activated complex [17-26,29,30] producing not only an increase of the reaction rate but also a modification of the selectivity. To study this effect, we have firstly carried out the reaction using a large pore Beta zeolite as catalyst. Thus, Figure 1 compares conversion results obtained for all silica Beta zeolite with that obtained during the thermal reaction or using Aerosil (amorphous non porous silica, BET surface area $=200 \mathrm{~m}^{2} \mathrm{~g}^{-1}$ ) as potential catalyst. Practically no differences were found on reaction rate nor on product distribution when the reaction occurs on nonporous silica, with Beta zeolite or even in absence of any solid. Considering that Aerosil is an amorphous solid, these results indicate that the catalytic reaction with pure silica Beta zeolite, if any, should only occur on the catalyst surface and the porous structure has not any effect on the reaction. Another hypothesis to explain these results is that diffusion of the products through the channels, if ever formed inside, is strongly restricted and the products remain adsorbed within the pores. To evaluate this second hypothesis, ${ }^{13} \mathrm{C}$ MAS NMR, elemental analysis and material balance were done, and the results obtained allow us to discard the accumulation of the reaction products inside the pores of the catalyst.

In order to check if the process is diffusion controlled within the pores of the zeolite and the reaction is mainly occurring on the external surface, the reaction was carried out with a pure silica nanocrystalline Beta (see Table 1). Table 1 shows differences between textural characteristics of all studied materials in this work. Figure 1 shows, an increase of the reaction rate when

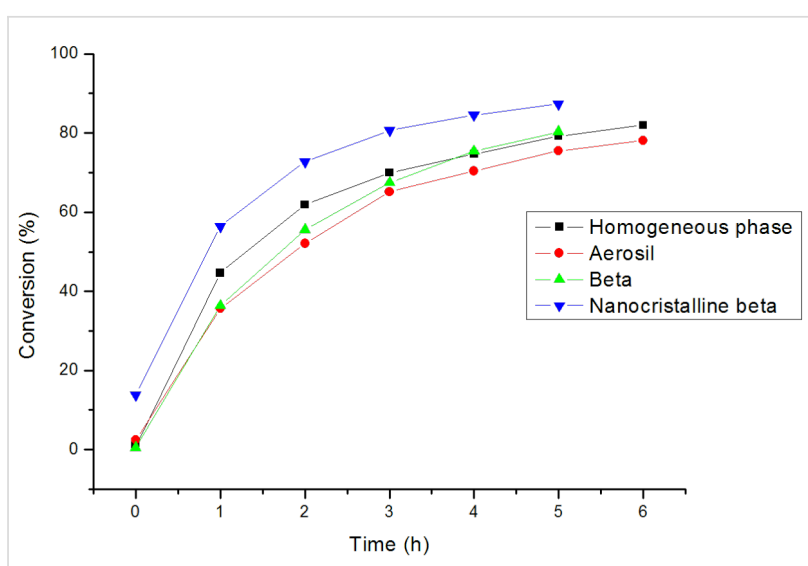

Figure 1: Conversion in the DAR catalysed by silica Beta zeolites and Aerosil.

reducing the crystallite size of the zeolite, indicating that there is a reactant diffusion control within the pores of Beta zeolite and consequently the reaction is mainly occurring in an outer shell of the crystals. If this is so, and since the reaction rate increases with the pure silica nanocrystalline Beta zeolite with an external surface area not too different from Aerosil silica, we can conclude that a concentration effect within the pore mouth of the zeolite may be responsible for the reaction rate enhancement observed with pure silica nanocristalline beta.

\section{Introduction of Lewis and Brønsted acid sites in the solids}

We have prepared Ti-Beta [31], Sn-Beta [32] and Al-Beta $(\mathrm{Si} / \mathrm{Al}=50)[33]$ considering that Lewis acid catalyzes the DAR [1]. This effect is known to occur by complexation of the carbonyl group of the dienophile with the Lewis acid that increases the electron deficiency of the dienophile, reducing the energy gap.

The results presented in Figure 2a, b clearly show an important increase in activity due to the presence of Brønsted and, espe-

Table 1: Textural characteristic of the studied materials.

\begin{tabular}{|c|c|c|c|c|}
\hline Catalyst & Area $\left(m^{2} g^{-1}\right)^{a}$ & Crystallite size $(\mu \mathrm{m})^{\mathrm{b}}$ & Metal content (wt \%) & External surface $\left(\mathrm{m}^{2} \mathrm{~g}^{-1}\right)^{\mathrm{d}}$ \\
\hline Beta & 457 & $0.5-1$ & - & 24 \\
\hline Nanocrystalline Beta & 595 & $0.015-0.02$ & - & 100 \\
\hline Ti-Beta & 454 & 1 & 1.2 & 25 \\
\hline Sn-Beta & 470 & 1 & 1.6 & 30 \\
\hline Beta Si/AI = 13 & 518 & $0.1-0.2$ & 2.8 & 34 \\
\hline Beta $\mathrm{Si} / \mathrm{Al}=50$ & 484 & 0.2 & 0.9 & 50 \\
\hline
\end{tabular}

${ }^{a}$ Area: Total area of the material per unit of mass. ${ }^{b}$ Crystallite size: Size of the crystalline material (aggregate of a large number of single crystals). It can vary from a few nanometers to several millimeters. ${ }^{c}$ Metal content: wt percentage of the metal content within the solid structure. ${ }^{d}$ External surface: External area of the material per unit of mass. 
a)

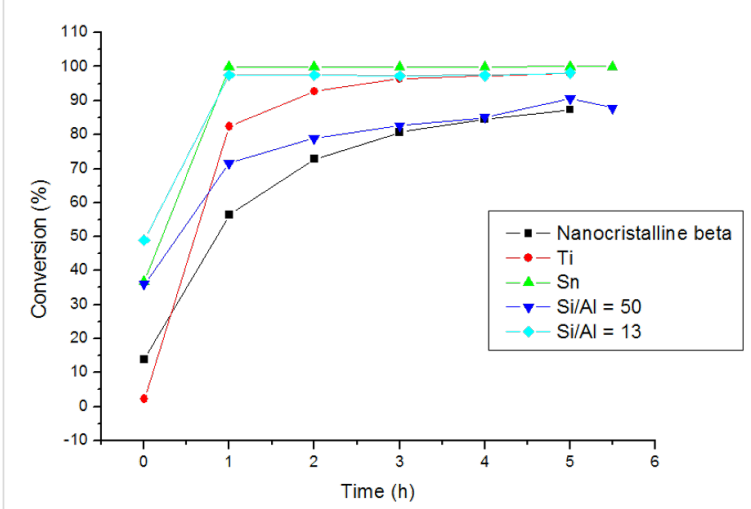

b)

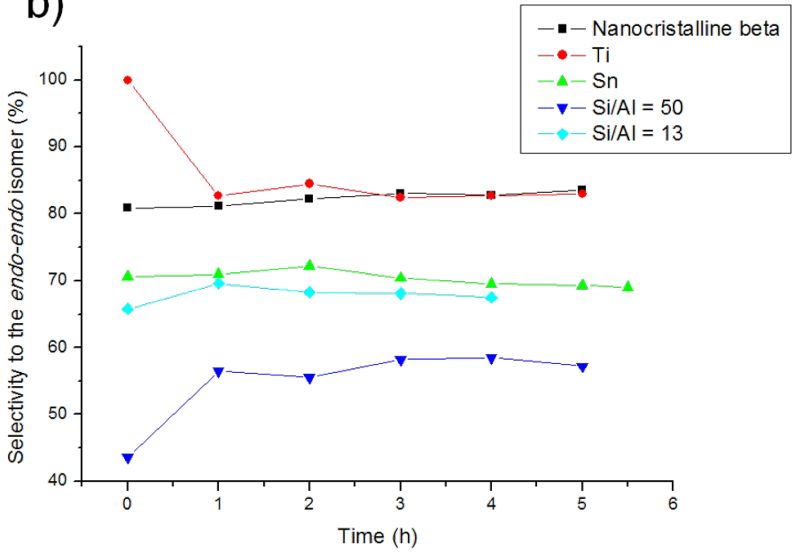

Figure 2: Effect of Lewis and Brønsted acid sites in the conversion (a) and selectivity (b) of the DAR.

cially, of Lewis acid sites. Indeed, despite the fact that the crystallite size of Ti- and Sn-Beta zeolites is much larger than Al-Beta (Table 1), the former give higher conversions.

Importantly, the catalytic effect on the selectivity of the competing retro-Diels-Alder reaction, which produces an enhancement of the endo-exo isomer from the endo-endo (see Scheme 1), is much lower for Ti-Beta and even for Al-Beta zeolites than for MCM-41 [30] (see Figure 2a, b) that owing to the retro-DA reaction the selectivity of the endo-endo isomer decreases from $85 \%$ to $65 \%$ as we previously reported. [30]

Considering the interesting application of beta zeolites as Lewis acid catalyst for Diels-Alder reactions in different fields, i.e., the formation of biofuels [34], it is important to get insight into the lack of catalytic activity of Beta for the retro-DAR, and elucidate whether this is a general effect with zeolites. Due to the diffusion limitations with Beta we have selected two extra-large pore zeolites, SSZ-53 (BET surface area $=377 \mathrm{~m}^{2} / \mathrm{g}$ ) and SSZ-59 (BET surface area $=383 \mathrm{~m}^{2} / \mathrm{g}$ ), with $1 \mathrm{D}$ pore system and $\mathrm{Si} / \mathrm{Al}$ ratio of 49 and 53, respectively. The results given in Figure 3 clearly show that the extra-large pore zeolites with pore diameters of $8.7 \AA$ and $8.5 \AA$ for SSZ-53 and SSZ-59, respectively, give higher conversions than Beta zeolite, despite the smaller crystallite size of the last. Interestingly, the retroDAR was neither observed with the two zeolites with extralarge pores. Similarly to that produced with the silica nanocrystalline Beta zeolite a concentration effect within the extra-large pore mouth may be responsible of the reaction rate enhancement observed with SSZ-53 and SSZ-59. a)

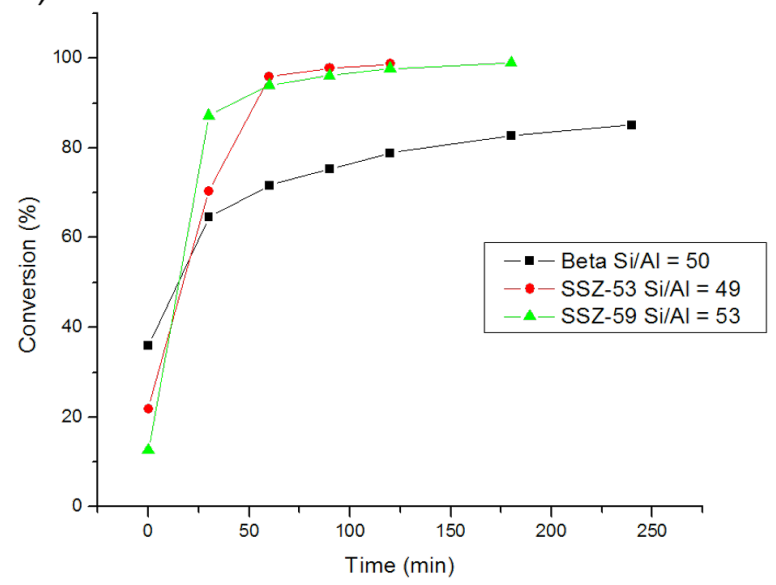

b)

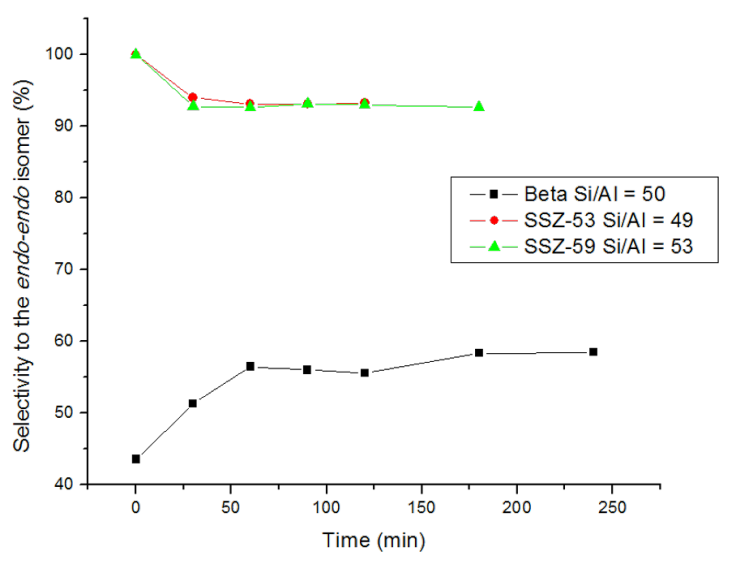

Figure 3: Effect of pore size in the conversion (a) and selectivity (b) of the DAR. 
Therefore, the results seem to confirm that the occurrence of retro-DAR as a competitive reaction not only depends on the presence of Brønsted centers as previously reported for materials with lower amounts of Al centers [28], but the structure of the material can play a determinant role. This represents an interesting observation since it will imply that, in principle, it should be possible to change the relative selectivity for DAR and retro-DAR working with micro or mesoporous catalysts.

Thus, Figure 4a,b compares conversion and selectivity to the endo-endo isomer with Al-Beta zeolite and the mesoporous MCM-41 material previously studied [30] both with very close $\mathrm{Si} / \mathrm{Al}$ ratios. It can be observed that both samples give the same conversion, but different selectivity behavior.

In the case of the microporous catalyst, Al-Beta zeolite, the selectivity to the endo-endo isomer remains constant with time, while with MCM-41 that is formed by larger channels, a continuous decrease of the endo-endo with time occurs and the thermodynamically controlled endo-exo product increases. The retro-Diels-Alder is a consecutive reaction that produces the thermodynamic product and it would occur if there is a certain confinement within the pores.

Thus, it was thought that if retro-DAR occurs in MCM-41 (40 $\AA$ ), if the pore size is decreased, then this reaction should be enhanced because of a certain confinement effect through the reactants. As it can be observed in Figure 4a,b, when the reaction was carried out with a mesoporous material of $\approx 20 \AA$ instead of $40 \AA$ but with a similar Si/Al ratio, the retro-DAR was enhanced, illustrating a certain confinement effect within the pores.

Two extra-large pore 3D zeolites with pore diameters of 1.2 (ITQ-33) [35] and $1.9 \mathrm{~nm}$ (ITQ-37) [36] have also been tested.
These are aluminosilicogermanates that, as the previously tested Al-zeolites or the Al-MCM-41 material, present Brønsted acidity. Interestingly, the pore diameters of ITQ-33, and more so ITQ-37 are close to the pore of the mesoporous MCM-41 presented above with $2.0 \mathrm{~nm}$. There is then a unique occasion to compare the catalytic behavior of an amorphous and a crystalline molecular sieve with practically the same pore diameter (Figure 5a,b).

As observed in Figure 5a,b, the crystalline structure of zeolites ITQ-33 and ITQ-37 do not favor neither the Diels-Alder cycloaddition between cyclopentadiene and $p$-benzoquinone, nor the retro-Diels-Alder reaction. This result suggests that the reaction takes place on the surface of the material and the pore structure does not have any influence on the reaction rate, neither for the DAR nor for the retro-DAR.

To further prove the effect of the structure, the reaction was carried out in presence of MCM-41 materials with different $\mathrm{Si} / \mathrm{Al}$ ratios, and similar pore diameter. The results are collected in Figure 6a,b. As it could be expected no differences were found in the conversion. Meanwhile, in the case of the selectivity it is possible to observe that increasing the Al content and lowering the pore size produces an increase in the selectivity of the endo-exo isomer. However, this effect is much more marked when the pore size decreases.

Finally, to conclude the catalytic study of the reaction between cyclopentadiene and $p$-benzoquinone in presence of Beta zeolites, the ability of reuse of Beta $\mathrm{Si} / \mathrm{Al}=50$ was examined. As shown in Figure 7a,b the activity of the catalyst decreases in some extension after repeated recycling. As expected for a less active catalyst, conversion falls partly while the selectivity to the kinetically controlled endo-endo isomer rises after recycling. a)

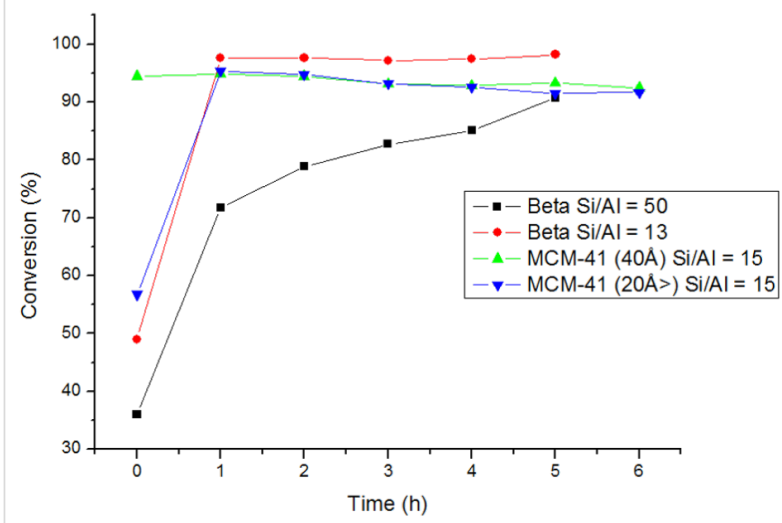

b)

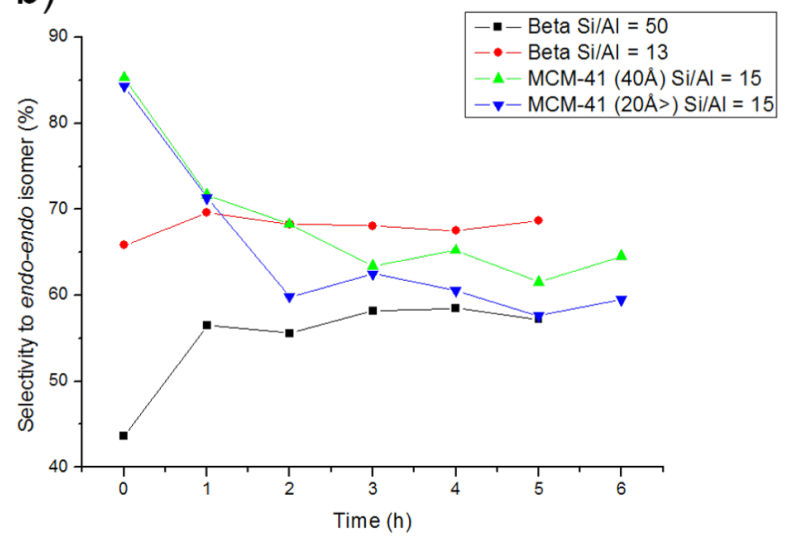

Figure 4: Comparison of conversion (a) and selectivity (b) of the DAR catalysed by Al-Beta zeolite and MCM-41. 

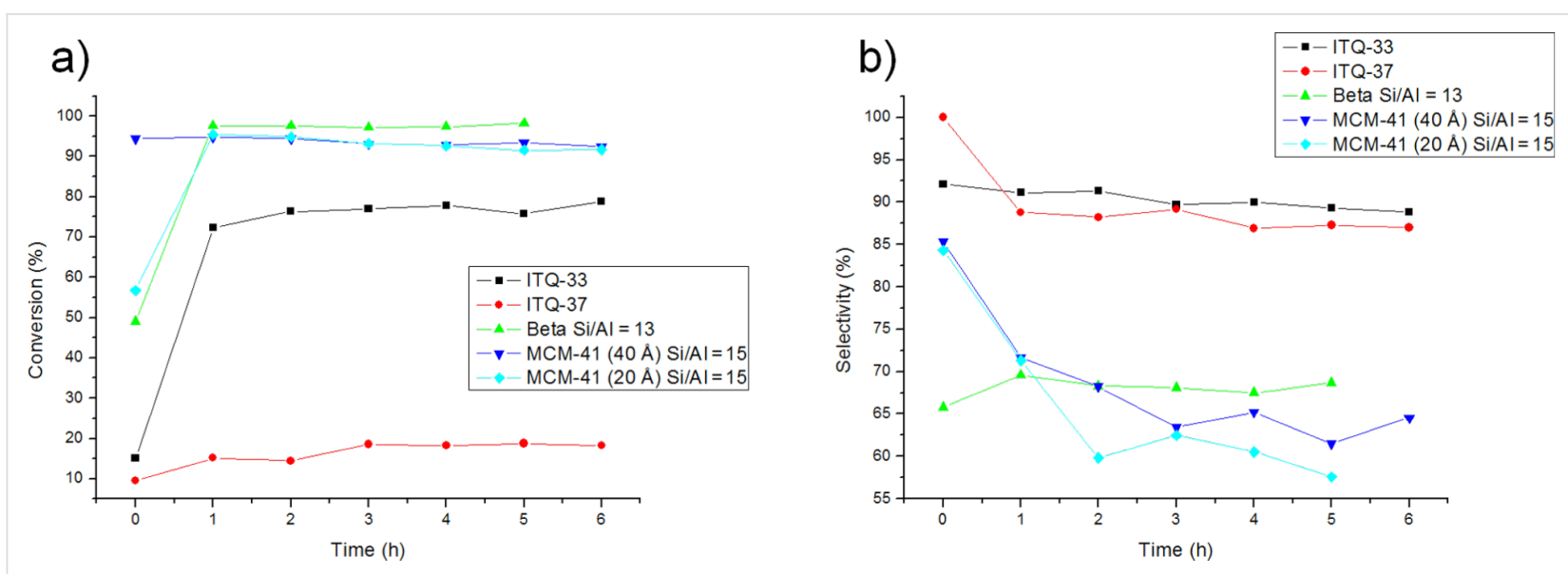

Figure 5: Comparison of conversion (a) and selectivity (b) of the DAR catalysed extra-large pore 3D zeolites.

a)

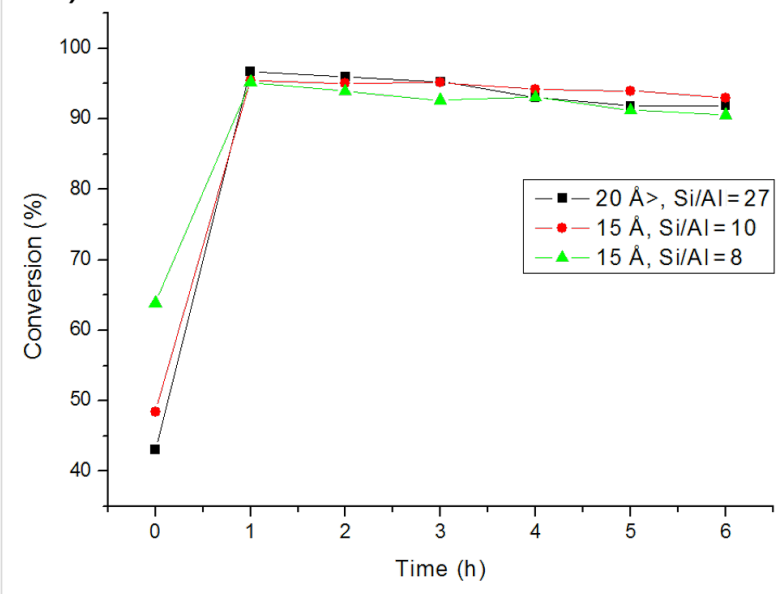

b)

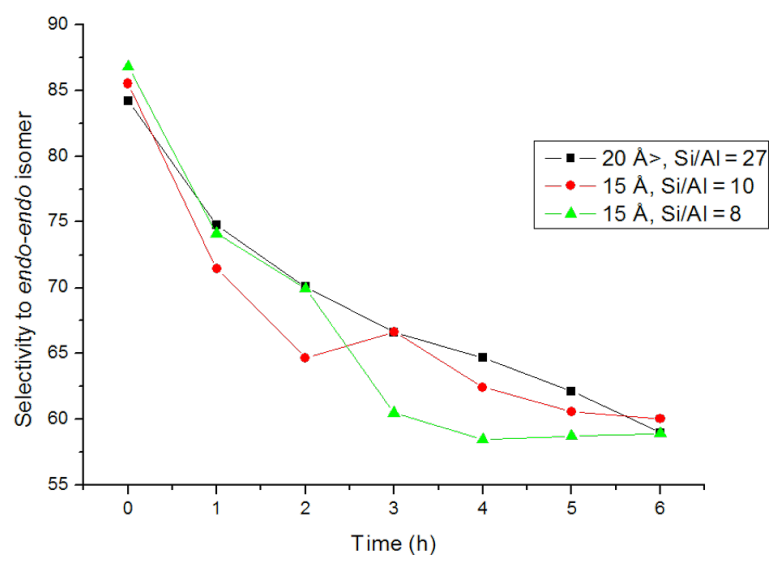

Figure 6: Effect of the Si/Al ratio in the conversion (a) and selectivity (b) of the DAR.

a)

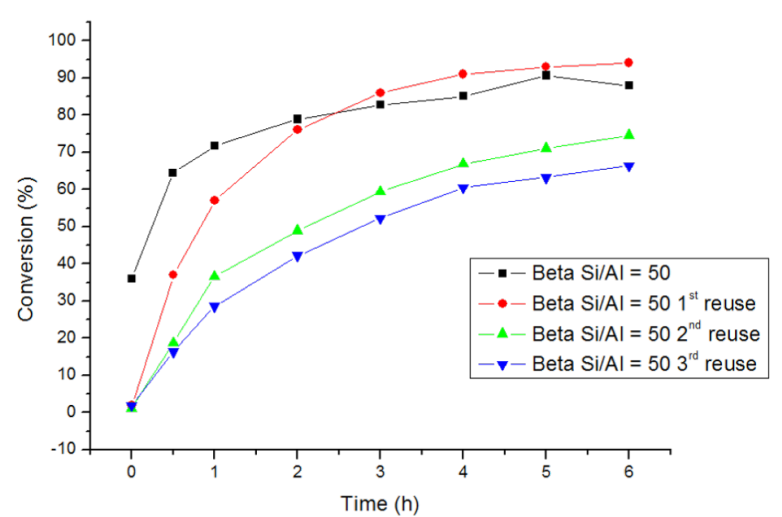

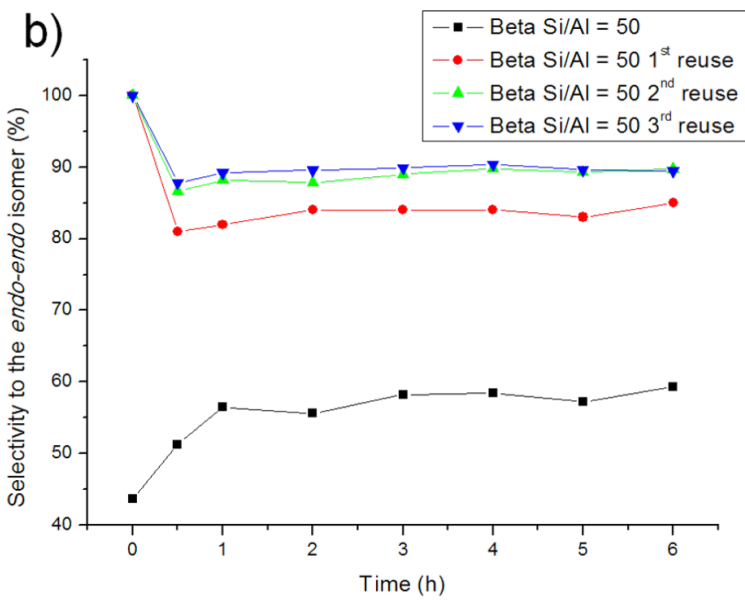

Figure 7: Effect of the reutilization of the catalysts in the conversion (a) and selectivity (b) of the DAR. 


\section{Conclusion}

In this work the DAR between cyclopentadiene and $p$-benzoquinone has been proved to take place on the catalyst surface when the reaction is carried out in presence of microporous materials, obtaining better results when a smaller crystal size catalyst is used.

When Lewis and Brønsted sites are inserted in the material structure, an improvement of the conversion degree is obtained as it occurs when MCM-41 and ITQ-2 were used [30]. However, a clear change in the selectivity behavior is observed. None of the used metals showed a retro-DAR enhancing reactivity, even Al, the best hydrogen-bond-donating agent. This result implies that the competitive retro-DAR takes place not only due to the capability to act as Brønsted sites of metallic centers, but also due to the structure of MCM-41 and ITQ-2. This effect can be used in order to obtain a selective product or the other isomer as a result of the chosen catalyst: The more Brønsted sites and the more confinement of the reactants, the more retro-DAR will be observed.

\section{Experimental}

\section{Catalyst preparation}

Beta zeolites [pure silica Beta, Beta (Ti), Beta (Sn) and Beta (Al)] were prepared according to [31-33], using tetraethylammonium hydroxide as template, tetraethyl orthosilicate (TEOS) as silica source and $\mathrm{Ti}(\mathrm{IV})$ ethoxide, $\mathrm{SnCl}_{4} \cdot 5 \mathrm{H}_{2} \mathrm{O}$ and metal $\mathrm{Al}$ as sources of heteroatoms. SSZ-53 and SSZ-59 were synthesized according to the procedures described in the literature [37-41]. The textural characteristics of the catalysts are given in Table 1.

\section{Catalytic tests}

In a similar manner as described in [30], after being activated at $250{ }^{\circ} \mathrm{C}$ under vacuum $\left(10^{-2} \mathrm{~mm} \mathrm{Hg}\right), 250 \mathrm{mg}$ of the corresponding calcined material were introduced into a two necked bottom flask under $\mathrm{N}_{2}$. Then, $108 \mathrm{mg}$ of $p$-benzoquinone $(1.0 \mathrm{mmol})$ and $10.0 \mathrm{~mL}$ of $\mathrm{CDCl}_{3}$ were added. The mixture was stirred at room temperature for a few minutes and $0.2 \mathrm{~mL}$ of freshly distilled cyclopentadiene $(3.0 \mathrm{mmol})$ were added with a syringe, being this moment considered $t=0 \mathrm{~h}$. The system was heated at $60{ }^{\circ} \mathrm{C}$ and samples were taken every hour, being directly analyzed by ${ }^{1} \mathrm{H}$ NMR.

Reaction products were isolated by HPLC using mixtures of $\mathrm{H}_{2} \mathrm{O} / \mathrm{MeOH} / \mathrm{MeCN}$ (45:50:5). Identification of these products was carried out by NMR techniques $\left({ }^{1} \mathrm{H},{ }^{13} \mathrm{C}\right.$, DEPT, COSY, HETCOR and NOE) being the spectral data fully coincident with those reported in the literature [42].
Conversion values for endo-endo and endo-exo products are always referred to conversion from the endo adduct. All compounds were previously described and fully characterized [30].

\section{Acknowledgements}

Financial support from the Ministerio de Economía y Competitividad through projects MAT2015-71261-R and CTQ201454987-P, are greatly acknowledged. M. V. Gómez thanks MINECO for participation in the Ramon y Cajal program. The authors thank M. Moliner, M. T. Navarro, S. Valencia for providing all the catalytic materials used in this study.

\section{References}

1. Yilmaz, Ö.; Kus, N. S.; Tunç, T.; Sahin, E. J. Mol. Struct. 2015, 1098, 72-75. doi:10.1016/j.molstruc.2015.06.012

2. Yamabe, S.; Dai, T.; Minato, T. J. Am. Chem. Soc. 1995, 117, 10994-10997. doi:10.1021/ja00149a023

3. Cativiela, C.; Fraile, J. M.; García, J. I.; Mayoral, J. A.; Pires, E.; Royo, A. J.; Figueras, F.; de Ménorval, L. C. Tetrahedron 1993, 49 4073-4084. doi:10.1016/S0040-4020(01)89919-1

4. Song, S.; Wu, G.; Dai, W.; Guan, N.; Li, L. J. Mol. Catal. A 2016, 420, 134-141. doi:10.1016/j.molcata.2016.04.023

5. Cativiela, C.; Fraile, J. M.; García, J. I.; Mayoral, J. A.; Figueras, F.; de Menorval, L. C.; Alonso, P. J. J. Catal. 1992, 137, 394-407. doi:10.1016/0021-9517(92)90167-G

6. Figueras, F.; Cativiela, C.; Fraile, J. M.; García, J. I.; Mayoral, J. A.; de Ménorval, L. C.; Pires, E. Stud. Surf. Sci. Catal. 1994, 83, 391-398. doi:10.1016/S0167-2991(08)63280-2

7. Eckert, C. A.; Grieger, R. A. J. Am. Chem. Soc. 1970, 92, 7149-7153. doi:10.1021/ja00727a021

8. Mimoto, A.; Nakano, K.; Ichikawa, Y.; Kotsuki, H. Heterocycles 2010, 80, 799-804. doi:10.3987/COM-09-S(S)85

9. Rideout, D. C.; Breslow, R. J. Am. Chem. Soc. 1980, 102, 7816-7817. doi:10.1021/ja00546a048

10. Wijnen, J. W.; Engberts, J. B. F. N. J. Org. Chem. 1997, 62, 2039-2044. doi:10.1021/jo9623200

11. Moliner, M. Dalton Trans. 2014, 43, 4197-4208. doi:10.1039/C3DT52293H

12. Climent, M. J.; Corma, A.; Iborra, S. Green Chem. 2014, 16, 516-547. doi:10.1039/c3gc41492b

13. Anastas, P. T.; Kirchhoff, M. M. Acc. Chem. Res. 2002, 35, 686-694. doi:10.1021/ar010065m

14. Brown, S. H. Zeolites in Catalysis. In Handbook of Green Chemistry; Green Catalysis, Heterogeneous Catalysis; Crabtree, R. H.; Anastas, P. T., Eds.; Wiley-VCH: Weinheim, Germany, 2009; Vol. 2, pp 1-50.

15. Corma, A. J. Catal. 2003, 216, 298-312. doi:10.1016/S0021-9517(02)00132-X

16. Corma, A.; García, H. Chem. Rev. 2003, 103, 4307-4366. doi:10.1021/cr030680z

17. Koehle, M.; Lobo, R. F. Catal. Sci. Technol. 2016, 6, 3018-3026. doi:10.1039/C5CY01501D

18. Kang, J.; Rebeck, J., Jr. Nature 1997, 385, 50-52. doi:10.1038/385050a0

19. Orazov, M.; Davis, M. E. Chem. Sci. 2016, 7, 2264-2274. doi:10.1039/C5SC03889H 
20. Chang, C.-C.; Cho, H. J.; Yu, J.; Gorte, R. J.; Gulbinski, J.; Dauenhauer, P.; Fan, W. Green Chem. 2016, 18, 1368-1376. doi:10.1039/C5GC02164B

21. Zendehdel, M.; Zamani, F.; Khanmohamadi, H. Microporous Mesoporous Mater. 2016, 225, 552-563. doi:10.1016/j.micromeso.2016.01.042

22. Onaka, M.; Yamasaki, R. Chem. Lett. 1998, 259-260. doi:10.1246/cl.1998.259

23. Kugita, T.; Ezawa, M.; Owada, T.; Tomita, Y.; Namba, S.; Hashimoto, N.; Osaka, M. Microporous Mesoporous Mater. 2001, 44-45, 531-536. doi:10.1016/S1387-1811(01)00231-1

24. Mahmoud, E.; Yu, J.; Gorte, R. J.; Lobo, R. F. ACS Catal. 2015, 5, 6946-6955. doi:10.1021/acscatal.5b01892

25. Green, S. K.; Patet, R. E.; Nikbin, N.; Williams, C. L.; Chang, C.-C.; Yu, J. Y.; Gorte, R. J.; Caratzoulas, S.; Fan, W.; Vlachos, D. G.; Dauenhauer, P. J. Appl. Catal., B 2016, 180, 487-496. doi:10.1016/j.apcatb.2015.06.044

26. Corma, A. Catal. Rev.: Sci. Eng. 2004, 46, 369-417. doi:10.1081/CR-200036732

27. Pacheco, J. J.; Labinger, J. A.; Sessions, A. L.; Davis, M. E. ACS Catal. 2015, 5, 5904-5913. doi:10.1021/acscatal.5b01309

28. Pacheco, J. J.; Davis, M. E. Proc. Natl. Acad. Sci. U. S. A. 2014, 111, 8363-8367. doi:10.1073/pnas.1408345111

29. Mashayekhi, G.; Ghandi, M.; Farzaneh, F.; Shahidzadeh, M.; Najafi, H. M. J. Mol. Catal. A: Chem. 2007, 264, 220-226. doi:10.1016/j.molcata.2006.09.032

30. Gómez, M. V.; Cantín, A.; Corma, A.; de la Hoz, A. J. Mol. Catal. A: Chem. 2005, 240, 16-21. doi:10.1016/j.molcata.2005.06.030

31. Blasco, T.; Corma, A.; Esteve, P.; Guil, J. M.; Martinez, A.; Perdigon-Melon, J. A.; Valencia, S. J. Phys. Chem. B 1998, 102, 75-88. doi:10.1021/jp973288w

32. Corma, A.; Nemeth, L. T.; Renz, M.; Valencia, S. Nature 2001, 412, 423-425. doi:10.1038/35086546

33. Camblor, M. A.; Corma, A.; Valencia, S. J. Mater. Chem. 1998, 8 2137-2145. doi:10.1039/a804457k

34. Dutta, S.; De, S.; Saha, B.; Alam, M. I. Catal. Sci. Technol. 2012, 2, 2025-2036. doi:10.1039/C2CY20235B

35. Corma, A.; Díaz-Cabañas, M. J.; Jordá, J. L.; Martínez, C.; Moliner, M. Nature 2006, 443, 842-845. doi:10.1038/nature05238

36. Sun, J.; Bonneau, C.; Cantín, Á.; Corma, A.; Díaz-Cabañas, M. J.; Moliner, M.; Zhang, D.; Li, M.; Zou, X. Nature 2009, 458, 1154-1157. doi:10.1038/nature07957

37. Elomari, S.; Zones, S. I. Zeolites and Mesoporous Materials at the Dawn of the 21st Century. In Proceedings of the 13th International Zeolite Conference, Vol. 153, Montpellier, France; Elsevier, 2001; pp 479-486.

38. Chen, C. Y.; Zones, S. I. Preparation of aluminum-, gallium-, and iron-exchanged borosilicate zeolites and their use as petroleum refining catalysts. U.S. Patent US 20030133870 A1, July 17, 2003.

39. Burton, A.; Elomari, S.; Chen, C.-Y.; Medrud, R. C.; Chan, I. Y.; Bull, L. M.; Kibby, C.; Harris, T. V.; Zones, S. I.; Vittoratos, E. S. Chem. - Eur. J. 2003, 9, 5737-5748. doi:10.1002/chem.200305238

40. Burton, A.; Elomari, S.; Chen, C. Y.; Harris, T. V.; Vittoratos, E. S., Eds. Recent Advances in the Science and Technology of Zeolites and Related Materials, Proceedings of the 14th International Zeolite Conference, Vol. 154A, pp 126-132., Cape Town, South Africa; Elsevier, 2004.

41. Elomari, S. Zeolite SSZ-53 prepared by using templating agent to be catalyst. U.S. Patent US 20020104780 A1, Aug 8, 2002.
42. Yates, P.; Switlak, K. Can. J. Chem. 1990, 68, 1894-1900. doi:10.1139/v90-293

\section{License and Terms}

This is an Open Access article under the terms of the Creative Commons Attribution License (http://creativecommons.org/licenses/by/4.0), which permits unrestricted use, distribution, and reproduction in any medium, provided the original work is properly cited.

The license is subject to the Beilstein Journal of Organic Chemistry terms and conditions:

(http://www.beilstein-journals.org/bjoc)

The definitive version of this article is the electronic one which can be found at: doi: $10.3762 /$ bjoc. 12.208 